\title{
Chemical Nanomanipulation of Two-Dimensional Nanosheets and Its Applications
}

\author{
Minoru Osada and Takayoshi Sasaki \\ International Center for Materials Nanoarchitectonics (MANA), \\ National Institute for Materials Science (NIMS), Tsukuba, Ibaraki, \\ Japan
}

\section{Introduction}

Two-dimensional (2D) nanosheets obtained via exfoliation of layered compounds have attracted intensive research in recent years, opening up new fields in the science and technology of 2D nanomaterials.1-6 These 2D nanosheets, which possess atomic or molecular thickness and infinite planar dimensions, are emerging as important new materials due to their unique properties. Research in such exotic 2D systems recently intensified as a result of emerging progress in graphene (carbon nanosheet) ${ }^{1,2}$ and novel functionalities in oxide nanosheets. ${ }^{3-5}$ In particular, oxide nanosheets are exceptionally rich in both structural diversity and electronic properties, with potential application in areas ranging from catalysis to electronics. Now, by using the exfoliation approach, it is possible to investigate dozens of different $2 \mathrm{D}$ oxide nanosheets in search of new phenomena and applications.

One of the important and attractive aspects of the exfoliated nanosheets is that various nanostructures can be fabricated using them as $2 \mathrm{D}$ building blocks. ${ }^{7-18}$ It is even possible to tailor superlattice-like assemblies, incorporating into the nanosheet galleries a wide range of materials such as organic molecules, polymers, and inorganic and metal nanoparticles. Sophisticated functionalities or nanodevices may be designed through the selection of nanosheets and combining materials, and precise control over their arrangement at the molecular scale.

In this chapter, we review the current research on oxide nanosheets. Our particular focus is placed on recent progress that has been made in the synthesis and properties of oxide nanosheets, highlighting emerging functionalities in electronic applications.

\section{Synthesis of oxide nanosheets}

Various nanosheets based on transition-metal oxides have been synthesized by delaminating the precursor crystals of layered oxide into their elemental layers (Table 1).

Chemical exfoliation is the most facile route for making isolation of single layers (oxide nanosheets) separately from thicker layered compounds (Fig. 1). These procedures have attracted much attention as an efficient method for preparing single layers with lateral sizes of up to several micrometers. Pioneering works in this line appeared in the 1990s by Sasaki 


\begin{tabular}{|l|l|l|}
\hline Ti oxide & $\begin{array}{l}\mathrm{Ti}_{0.91} \mathrm{O}_{2}, \mathrm{Ti}_{0.87} \mathrm{O}_{2}, \mathrm{Ti}_{0.8} \mathrm{Co}_{0.2} \mathrm{O}_{2}, \mathrm{Ti}_{0.6} \mathrm{Fe}_{0.4} \mathrm{O}_{2}, \mathrm{Ti}_{5.2-2 x)} \\
\mathrm{Mn}_{x / 2} \mathrm{O}_{2}(0 \leq x \leq 0.4) \mathrm{Ti}_{0.8-x} / 4 \mathrm{Fe}_{x / 2} \mathrm{Co}_{0.2-x / 4} \mathrm{O}_{2}(0 \leq x \leq 0.8)\end{array}$ & $\begin{array}{l}\text { Semiconducting, } \\
\text { Photocatalytic, } \\
\text { Dielectric, } \\
\text { Ferromagnetic }\end{array}$ \\
\hline Mn oixde & $\mathrm{MnO}_{2}$ & Redoxable \\
\hline $\begin{array}{l}\mathrm{Nb} / \mathrm{Ti} \text { and } \\
\text { Ta oxide }\end{array}$ & $\mathrm{Nb}_{6} \mathrm{O}_{17}, \mathrm{Nb}_{3} \mathrm{O}_{8}, \mathrm{TiNbO}_{5}, \mathrm{Ti}_{2} \mathrm{NbO}_{7}, \mathrm{Ti}_{5} \mathrm{NbO}_{14}, \mathrm{TaO}_{3}$ & $\begin{array}{l}\text { Photocatalytic, } \\
\text { Dielectric }\end{array}$ \\
\hline Perovksite & $\begin{array}{l}\mathrm{Gd}_{1.4} \mathrm{Eu}_{0.6} \mathrm{Ti}_{3} \mathrm{O}_{10}, \mathrm{Bi}_{4} \mathrm{Ti}_{3} \mathrm{O}_{12}, \mathrm{LaNb}_{2} \mathrm{O}_{7}, \mathrm{La}_{0.9} \mathrm{Eu}_{0.05} \mathrm{Nb}_{2} \mathrm{O}_{7}, \\
\mathrm{SrTa}_{2} \mathrm{O}_{7}, \mathrm{La}_{0.7} \mathrm{~Tb}_{0.3} \mathrm{Ta}_{2} \mathrm{O}_{7}, \mathrm{Eu}_{0.56} \mathrm{Ta}_{2} \mathrm{O}_{7}, \mathrm{Ca}_{2} \mathrm{Nb}_{3} \mathrm{O}_{10},\end{array}$ & $\begin{array}{l}\text { Photocatalytic, } \\
\text { Dielectric, } \\
\text { Photoluminescence }\end{array}$ \\
\hline Mo oxide & $\mathrm{MoO}_{2} \mathrm{O}_{10}, \mathrm{Ca}_{2} \mathrm{Ta}_{3} \mathrm{O}_{10}, \mathrm{Sr}_{2} \mathrm{Ta}_{3} \mathrm{O}_{10}$ & Conducting \\
\hline Ru oxide & $\mathrm{RuO}_{2.1}, \mathrm{RuO}_{2}$ & $\begin{array}{l}\text { Redoxable, } \\
\text { Conducting }\end{array}$ \\
\hline W oxide & $\mathrm{W}_{2} \mathrm{O}_{7}, \mathrm{Cs}_{4} \mathrm{~W}_{11} \mathrm{O}_{36}$ & $\begin{array}{l}\text { Redoxable } \\
\text { Photochromic }\end{array}$ \\
\hline
\end{tabular}

Table 1. Library of oxide nanosheets

et al.,19, 20 reporting the successful delamination of layered titanates into single titanate nanosheets. Prompted by the findings related to functional oxide nanosheets, several strategies on functional oxides can be found in the literature.

\section{Layer Compound}

Colloidal Suspension

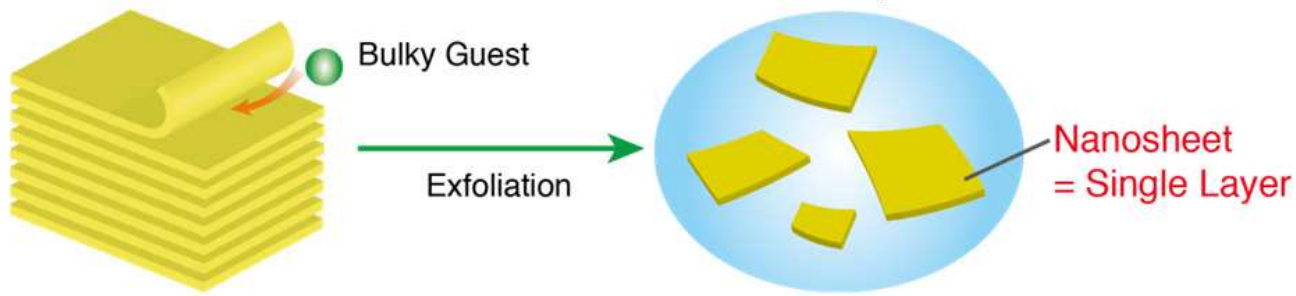

Fig. 1. Schematic illustration for the exfoliation of a layer compound into nanosheets.

In the case of metal oxides, protonation usually resulted in electrostatic repulsions that facilitated exfoliation. By this procedure, single layers of Ti oxides, ${ }^{19-22} \mathrm{Mn}$ oxides, ${ }^{23} \mathrm{Nb} / \mathrm{Ta}$ oxides, ${ }^{24-26}$ Mo oxides, ${ }^{27} \mathrm{Ru}$ oxides, ${ }^{28}$ and $\mathrm{W}$ oxides, ${ }^{29}$ as well as sheets of several perovskites 7 , 9, 30-35 have been separated from bulk samples (Fig. 2).

In these cases, a chemical intercalator that assists the separation of layers and hampers the reassembly of the bulk lamellar material is always required. Tetrabutylammonium (TBA) is the most commonly used intercalator, but also tetrametylammonium and ethylammonium have been used successfully for these purposes. Layered transition-metal oxides such as $\mathrm{Cs}_{0.7} \mathrm{Ti}_{1.825} \Upsilon_{0.175} \mathrm{O}_{4}$ ( $\Upsilon$ : vacancy), $\mathrm{K}_{0.45} \mathrm{MnO}_{2}$, and $\mathrm{KCa}_{2} \mathrm{Nb}_{3} \mathrm{O}_{10}$ can be used as the starting material for the nanosheet.19, 20, 23, 31 A common feature of these host compounds is cationexchange properties involving interlayer alkali metal ions, which are a key to facilitating exfoliation. As the first step to delamination, these layered materials are acid-exchanged into protonated forms such as $\mathrm{H}_{0.7} \mathrm{Ti}_{1.825} \Upsilon_{0.175} \mathrm{O}_{4} \bullet \mathrm{H}_{2} \mathrm{O}, \mathrm{H}_{0.13} \mathrm{MnO}_{2} \bullet 0.7 \mathrm{H}_{2} \mathrm{O}$, and 
$\mathrm{HCa}_{2} \mathrm{Nb}_{3} \mathrm{O}_{10} \bullet 1.5 \mathrm{H}_{2} \mathrm{O}$, in which the interlayer alkali metal ions can be completely removed under suitable conditions while maintaining the layered structure. The resulting protonic oxides are subsequently delaminated through reaction with a solution containing TBA ions, producing turbid colloidal suspensions of $\mathrm{Ti}_{0.91} \mathrm{O}_{2}, \mathrm{MnO}_{2}$, and $\mathrm{Ca}_{2} \mathrm{Nb}_{3} \mathrm{O}_{10}$ nanosheets. Such an exfoliation process is quite general: exfoliation of the other layered host compounds proceeds in a similar fashion.

(a)

$$
\mathrm{Ti}_{0.91} \mathrm{O}_{2}
$$

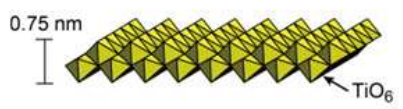

(b)

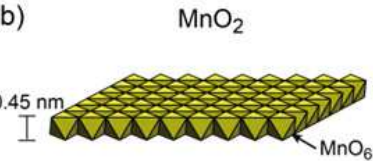

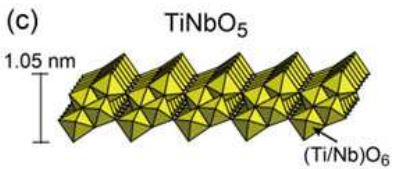

(d)

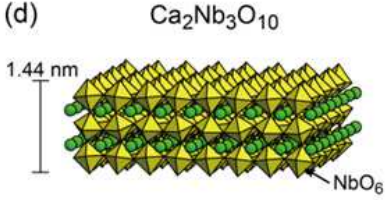

(e)

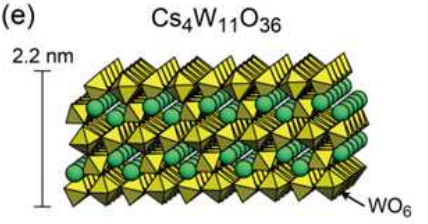

Fig. 2. Strucutres of selected oxide nanosheets. (a) $\mathrm{Ti}_{0.91} \mathrm{O}_{2}$, (b) $\mathrm{MnO}_{2}$, (c) $\mathrm{TiNbO}_{5}$, (d) $\mathrm{Ca}_{2} \mathrm{Nb}_{3} \mathrm{O}_{10}$, (e) $\mathrm{Cs}_{4} \mathrm{~W}_{11} \mathrm{O}_{36}$.

These materials have prompted many efforts to elucidate their structural properties. The formation of unilamellar nanosheets was confirmed by direct observation with atomic force microscopy (AFM), x-ray diffraction (XRD), and transmission electron microscopy (TEM). ${ }^{36-}$ 40 Fig. 3 depicts an AFM image for $\mathrm{Ti}_{0.87} \mathrm{O}_{2}$ nanosheets. The AFM data clearly reveals a sheetlike morphology, which is inherent to the host layer in the parent compounds. The average thickness was $0.93 \pm 0.1 \mathrm{~nm}$. This value is nearly comparable to the crystallographic thickness of the host layer in the corresponding parent compound, supporting the formation of unilamellar nanosheets. On the other hand, the lateral size depends on the choice of starting materials. For nanosheets derived from polycrystalline powder samples, the lateral size ranges from submicrometers to several tens of micrometers. After tuning the exfoliation conditions by using flux-grown single crystals, the technique provides high-quality nanosheet crystallites up to $\sim 100 \mu \mathrm{m}$ in size, which is suitable for electronic applications. ${ }^{21}$

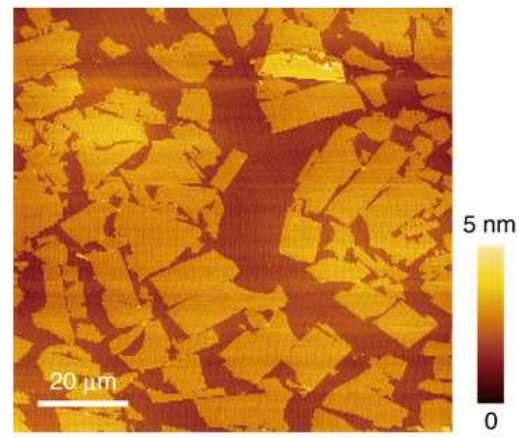

Fig. 3. AFM image of $\mathrm{Ti}_{087} \mathrm{O}_{2}$ nanosheets dispersed on a Si substrate. 


\section{Chemical nanomanipulation of oxide nanosheets}

Oxide nanosheets are an important and promising component for creating new materials. Oxide nanosheets have a high $2 \mathrm{D}$ anisotropy of the crystallites: thickness is $\sim 1 \mathrm{~nm}$ wheras lateral size ranges from submicrometers to $\sim 100 \mu \mathrm{m}$. In addition, these nanosheets are obtained as negatively charged crystallites that are dispersed in a colloidal suspension. These aspects make the nanosheets a suitable building block for designing nanostructured films. In practice, colloidal nanosheets can be organized into various nanostructures or combined with a range of foreign materials at the nanometer scale by applying wet-process synthetic techniques involving flocculation and layer-by-layer (LbL) self-assembly. Through these processes, oxide nanosheets can be combined with a wide range of polyions such as organic polyelectrolytes, metal complexes, clusters and even oppositely charged nanosheets, which is a major advantage of this approach. Furthermore, control of particulate shape as thin flakes and hollow spheres has been achieved through freeze- or spray-drying techniques.

One of the highlights is the fabrication of nanocomposite films of organic polymer/nanosheet materials that exhibit useful properties. Several groups have demonstrated that the electrostatic LbL self-assembly via sequential adsorption and Langmuir-Blodgett (LB) procedure are effective for this purpose (Fig. 4).

(a) Electrostatic Sequential Deposition

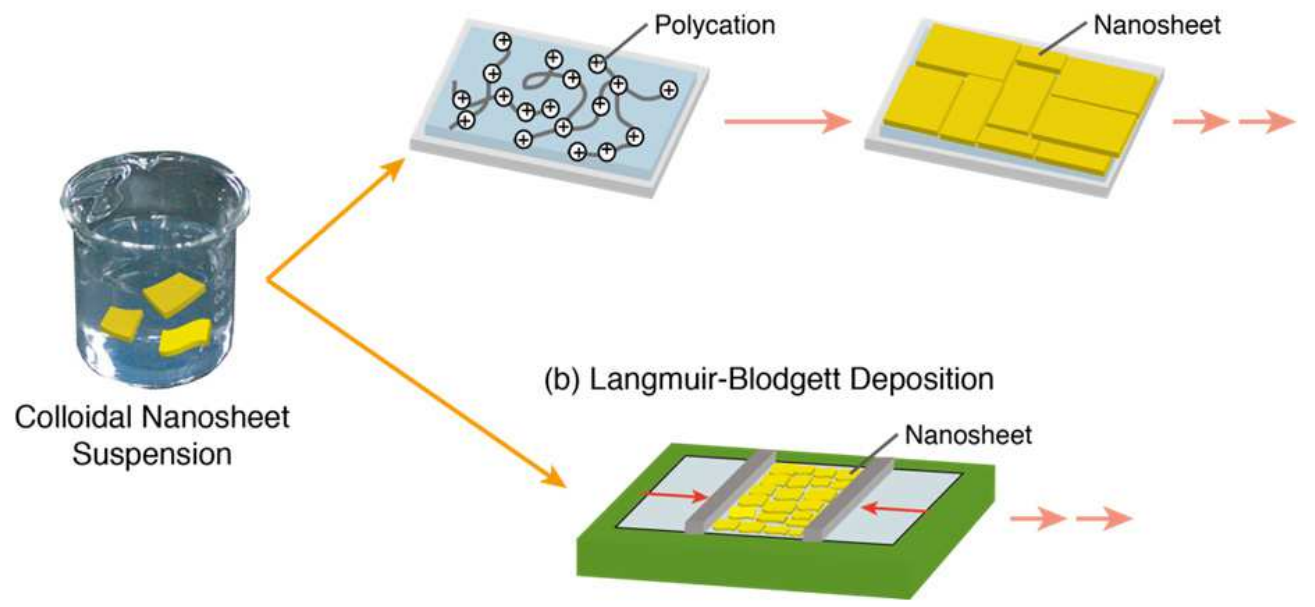

Fig. 4. Schematic illustration for chemical nanomanipulation of oxide nanosheets. (a) Electrostatic sequential deposition and (b) Langmuir-Blodgett deposition.

Electrostatic sequential deposition is one of the most powerful methods of fabricating nanostructured multilayer films with precisely controlled composition, thickness and architecture on a nanometer scale [Fig. 4(a)]. This technique, often called "molecular beaker epitaxy", has been first developed by Decher ${ }^{41}$ and applied to various charged materials. In this LbL process, a multilayer assembly can be built up by alternately dipping the substrate in a colloidal suspension of nanosheets and an aqueous solution of suitable polyelectroytes. Polycations such as poly (diallyldimethylammonium chloride) (PDDA) and poly (ethylenimine) are usually used as a counterpart of the oxide nanosheets. Fig. 5(a) depicts an 
example of the multilayer film of (PDDA/ $\left.\mathrm{Ti}_{0.91} \mathrm{O}_{2}\right)_{10}$ on a quartz glass substrate, showing UV-visible absorption spectra in the fabrication process. The absorption peak at $265 \mathrm{~nm}$, attributable to the $\mathrm{Ti}_{0.91} \mathrm{O}_{2}$ nanosheets, was progressively enhanced as the number of deposition cycles increased, clearly indicating the repeated adsorption of nearly equal amounts of nanosheets. XRD data provides further evidence for the formation of multilayer films by the evolution of Bragg peaks and their progressive enhancement. Other characterizations by ellipsometry, FT-IR and AFM all support the growth of multilayer nanocomposite films. Multilayer films of other nanosheets were fabricated by similar procedures.
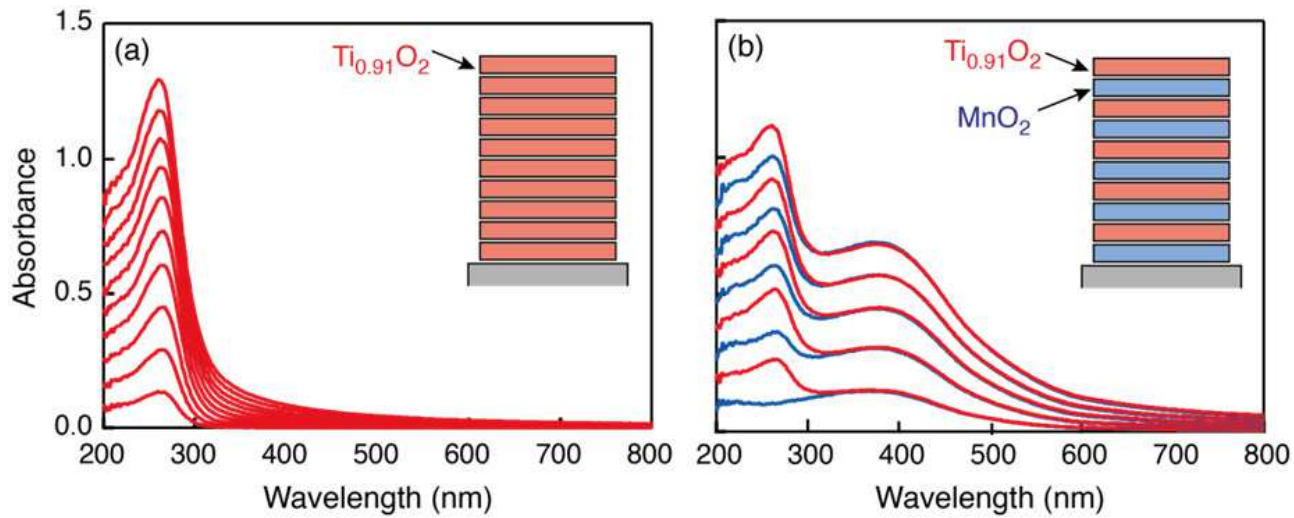

Fig. 5. UV-visible absorption spectra in the multilayer buildup processes for $\left(\mathrm{Ti}_{0.91} \mathrm{O}_{2} / \mathrm{PDDA}\right)_{10}(\mathrm{a})$ and $\left(\mathrm{PDDA} / \mathrm{Ti}_{0.91} \mathrm{O}_{2} / \mathrm{PDDA} / \mathrm{MnO}_{2}\right)_{10}(\mathrm{~b})$. The insets indicate the designed stacked structures of the nanosheets.

Such LbL assembly of various nanosheets also allows us to tailor superlattices or heterostructures by tuning the number of nanosheets and their stacking sequences. Fig. 5(b) shows UV-visible absorption spectra for the superlattice assembly composed of $\mathrm{MnO}_{2}$ and $\mathrm{Ti}_{0.91} \mathrm{O}_{2}$ nanosheets. The observed spectral changes clearly indicate that the films grew as designed. The superlattice approach makes it possible to design complex functions that cannot be achieved using a single material.

LB deposition has been proved much simple and effective as another approach for organizing 2D nanosheets [Fig. 4(b)]. ${ }^{42-45}$ LB film deposition, the formation of a floating monolayer on water surface in a Langmuir trough followed by an appropriate level of compression, is preferable for achieving dense packing or neat tiling. Through verticaldipping/lifting, the monolayer is deposited onto a flat substrate in LbL fashion. Pioneering work ${ }^{42}$ has demonstrated that exfoliated nanosheets could float by adhering to amphiphilic ammonium cations at the air/water interface through electrostatic interaction, and thus the ordinary LB procedure is applicable for fabricating nanosheet films. Although LB technique has been used for decades, its application for nanoparticles and nanorods is often frustrated by defects ranging from pinholes to larger reorganization of the layers. In the case of nanosheets, the LB technique provides nearly perfect mono- and multilayer films with atomically flat surfaces. The LB-based LbL approach with the use of an atomically flat substrate is effective for fabricating atomically uniform and highly dense nanofilms of oxide nanosheets. Fig. 6 shows a cross-sectional high-resolution TEM image of a 5-layer $(7.5 \mathrm{~nm}$ 
thick) $\mathrm{Ca}_{2} \mathrm{Nb}_{3} \mathrm{O}_{10}$ film on a $\mathrm{SrRuO}_{3}$ substrate. ${ }^{46}$ The image clearly reveals a stacking structure corresponding to the LbL assembly of nanosheets. Such LB-deposited nanofilms are very suitable for a number of applications in electronic devices.

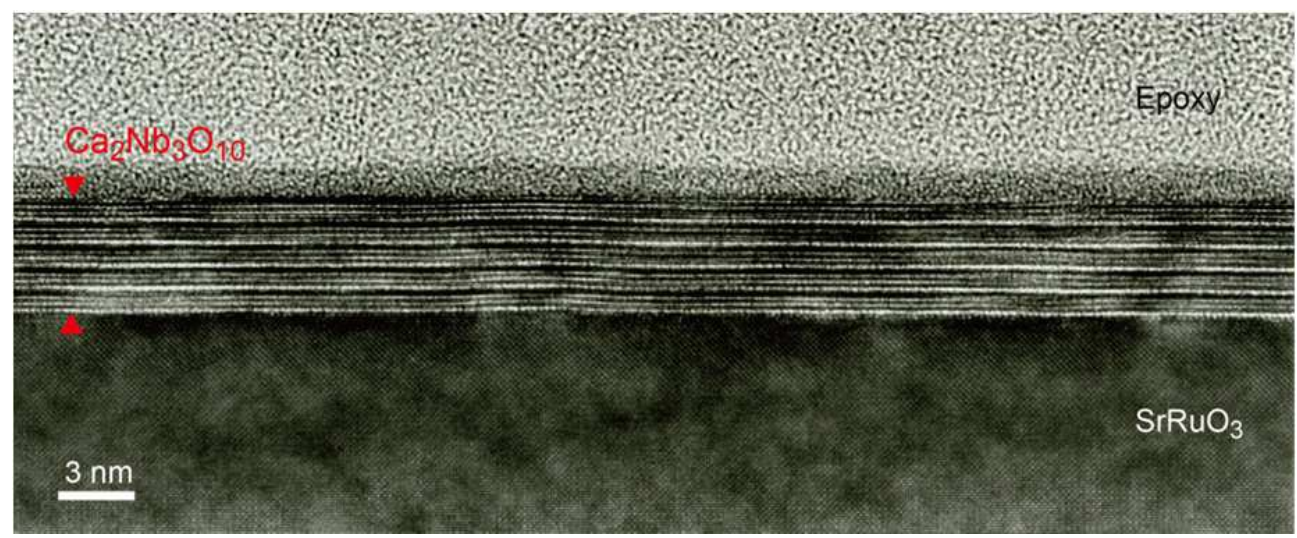

Fig. 6. Cross-sectional high-resolution TEM image of a 5-layer ( $7.5 \mathrm{~nm}$ thick) $\mathrm{Ca}_{2} \mathrm{Nb}_{3} \mathrm{O}_{10}$ film on a $\mathrm{SrRuO}_{3}$ substrate. Note that the film/substrate interface is atomically flat without an interfacial layer between $\mathrm{Ca}_{2} \mathrm{Nb}_{3} \mathrm{O}_{10}$ and $\mathrm{SrRuO}_{3}$ substrate. The nanofilms of this quality show an excellent dielectric property as will be discussed in section 4.1.

A clear benefit of these LbL approaches is the engineering of the clean interface, which appears to be a key step in the design of film properties. Currently, physical depositions such as vapor deposition and laser ablation are the main methods of fabricating oxide films. These techniques, however, usually require a complex and difficult deposition process involving high-temperature postannealing $\left(>600^{\circ} \mathrm{C}\right)$, which can cause degradation in the film-substrate interface arising from both nonstoichiometry and thermal stress. In that scence, the solution-based bottom-up fabrication using oxide nanosheets provides new opportunities for room-temperature fabrication of oxide nanoelectronics, while eliminating integration problems encountered in current film-growth techniques.

\section{Electronic applications}

The development of a wide range of nanosheets with various properties is very important in the design of nanodevices with sophisticated functionality. Currently, extensive effort is being made to develop oxide nanosheets with new physical and chemical properties. The range of applications of nanoassemblies could therefore be widened significantly. Here, we describe the current status of researches on oxide nanosheets, highlighting emerging functionalities in electronic applications.

\subsection{Electronic devices}

In nanosheets, 2D structures created by lateral confinement can potentially lead to not only the modification of electronic structures but also the modulation of electron-transport phenomena that arise from the quantum confinement effect. Research in such exotic 2D systems recently intensified as a result of emerging progress in graphene and its novel 
functionalities.1, 2, 47 In graphene, a number of unique conducting phenomena have already been found, such as anomalous quantum Hall effect, bipolar supercurrent, etc.

Despite the similar 2D structural nature, oxide nanosheets are quite different electronically (Table 1). Most oxide nanosheets synthesized to date are $d^{0}$ transition metal oxides (with $\left.\mathrm{Ti}^{4+}, \mathrm{Nb}^{5+}, \mathrm{Ta}^{5+}, \mathrm{W}^{6+}\right)$, where the empty $d$ orbitals of metal mix with the filled $p$ orbitals of the ligands. ${ }^{48}$ Such $d^{0}$ materials are not electronically interesting, but semiconducting or insulating materials. In current research on oxide nanosheets, experimental efforts have thus focused on their use as a semiconducting host or dielectric.

$\mathrm{Ti}_{0.91} \mathrm{O}_{2}$ nanosheets possess semiconducting properties similar to those of bulk $\mathrm{TiO}_{2}$, such as rutile and anatase except for some modifications due to size quantization. ${ }^{4}{ }^{2} \mathrm{Ti}_{0.91} \mathrm{O}_{2}$ nanosheets generate anodic photocurrent by band gap excitation under light irradiation with wavelengths shorter than $320 \mathrm{~nm}$, corresponding to wider band gap energy of $3.8 \mathrm{eV} .50$ In contrast, $\mathrm{MnO}_{2}$ nanosheets have a broad absorption peak centered at $372 \mathrm{~nm}$, which results from $d$ - $d$ transitions in the $\mathrm{MnO}_{2}$ nanosheets. ${ }^{13}$ Various interesting and useful properties have also been developed by organizing or assembling these oxide nanosheets into composite materials or multilayer films. $\mathrm{Ti}_{0.91} \mathrm{O}_{2}$ nanosheets flocculated with lanthanide cations emitted intense photoluminescence at room temperature through effective energy transfer from the semiconducting nanosheet host. ${ }^{15}$, 51 Highly stable photoinduced charge separation was attained in a composite film of restacked $\mathrm{Ti}_{0.91} \mathrm{O}_{2}$ nanosheets and mesoporous silica or clay minerals, in which electron donors and acceptors are spatially separated at a distance of micrometers.

Another enticing possibility is the use of oxide nanosheets in high- $\kappa$ dielectrics, a key material for future semiconducting technology. For example, $\mathrm{Ti}_{0.87} \mathrm{O}_{2}$ and $\mathrm{Ca}_{2} \mathrm{Nb}_{3} \mathrm{O}_{10}$ nanosheets act as high- $\kappa$ nanoblocks, and their multilayer assemblies exhibit low leakage current density $\left(<10^{-7} \mathrm{Acm}^{-2}\right)$ with a high dielectric constant of $>100$ even for thicknesses as low as $10 \mathrm{~nm} .43,46,52-55$ Fig. 7 summarizes the $\varepsilon_{r}$ values for oxide nanosheets and various high- $\kappa$ oxides. In the ultrathin region $(<20 \mathrm{~nm})$, the $\varepsilon_{r}$ values of $\mathrm{Ti}_{0.87} \mathrm{O}_{2}$ and $\mathrm{Ca}_{2} \mathrm{Nb}_{3} \mathrm{O}_{10}$ nanosheets are larger than the values reported for any other high- $\kappa$ materials. It should be noted that the high $\varepsilon_{r}$ values of $\mathrm{Ti}_{0.87} \mathrm{O}_{2}$ and $\mathrm{Ca}_{2} \mathrm{Nb}_{3} \mathrm{O}_{10}$ nanosheets persist even in the $<10$ $\mathrm{nm}$ region, which is in sharp contrast to a size-induced dielectric collapse in $\left(\mathrm{Ba}_{1-x} \mathrm{Sr}_{x}\right) \mathrm{TiO}_{3} \cdot{ }^{56}$, 57 These results suggest that $\mathrm{Ti}_{0.87} \mathrm{O}_{2}$ and $\mathrm{Ca}_{2} \mathrm{Nb}_{3} \mathrm{O}_{10}$ are a very promising candidate for high$\kappa$ applications such as high-density capacitors and gate dielectrics.

Oxide nanosheets are reported to be an excellent material for electric batteries. In particular, owing to their unique 2D morphology, it is expected that laterally confined 2D nanosheet crystals can significantly enhance the host capabilities of active electrode materials. $\mathrm{RuO}_{2.1}$ nanosheets showed high performance as electrochemical supercapacitors. ${ }^{28}$ Reassembled $\mathrm{Ti}_{0.91} \mathrm{O}_{2}$ or $\mathrm{MnO}_{2}$ nanosheets, either with or without carbon, are reported to have as large a capacity as Li-ion batteries. ${ }^{14,}{ }^{58-60}$ Multilayer films of $\mathrm{MnO}_{2}$ nanosheets prepared on ITO substrate also exhibited electrochromic behavior associated with the electrochemical redox process between $\mathrm{Mn}^{3+}$ and $\mathrm{Mn}^{4+} .61$ This electrochromic efficiency is estimated to be $64.2 \mathrm{~cm}^{2} \mathrm{C}^{-1}$ at $385 \mathrm{~nm}$, which is a relatively high value among manganese oxides.

An alternative route to nanosheet-based electronics is to consider oxide nanosheet not as an active component for nanodevices but as a seed layer, in which 1-nm-thick monolayer films can be used for design and orientation control of crystal films. ${ }^{62-64}$ The idea is to exploit the advantage of oxide nanosheets having high thermal stability even in ultrathin form. Such a technique is expected to have great potential for advances in thin-film technology. 


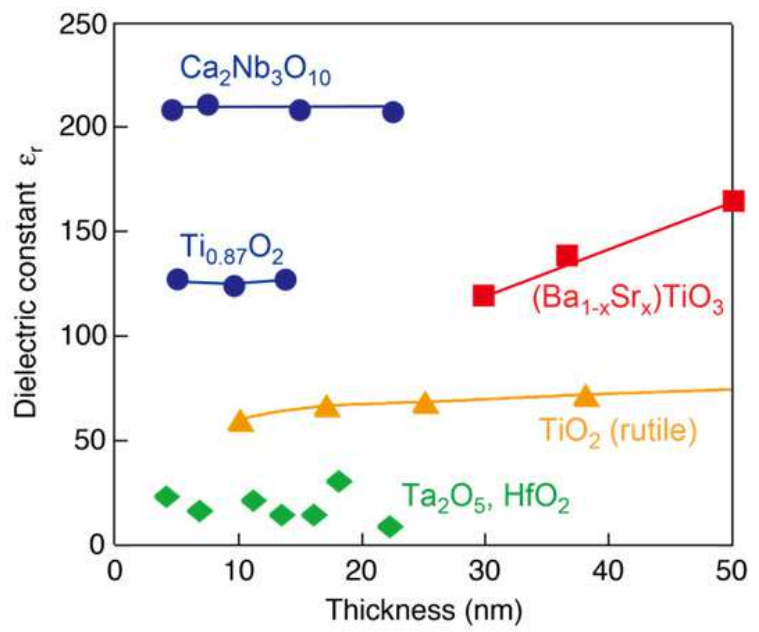

Fig. 7. The $\varepsilon_{r}$ values for oxide nanosheets and various high- $\kappa$ oxides.

\subsection{Spin-electronic devices}

Recent interest in room-temperature (RT) ferromagnetic semiconductors and lowdimensional magnetic nanostructures (motivated by possible application in spin-electronic devices) has stimulated research in the synthesis and characterization of $\mathrm{TiO}_{2}$ nanosheet based materials. Titania nanosheets substituted with magnetic elements ( $\mathrm{Co}, \mathrm{Fe}, \mathrm{Mn})$ are ferromagnetic at room temperature.65 The magnetization of $\mathrm{Ti}_{0.8} \mathrm{Co}_{0.2} \mathrm{O}_{2}$ nanosheets is anisotropic due to the 2D nature, and a maximum magnetic moment of $1.4 \mu_{\mathrm{B}} / \mathrm{Co}$ for $\mathrm{H} / /$ film is obtained, which is greater than the spin moment of $1 \mu_{\mathrm{B}} /$ Co theoretically expected for low-spin $\mathrm{Co}^{2+}$ as well as that in Co-doped anatase with semiconducting $\left(0.3 \mu_{\mathrm{B}} / \mathrm{Co}\right)$ and insulating $\left(1.1 \mu_{\mathrm{B}} / \mathrm{Co}\right)$ grounds. 65,66 Similar ferromagnetic properties have also been reported in a series of substituted and co-substituted titania nanosheets, including $\mathrm{Ti}_{0.8} \mathrm{Co}_{0.2} \mathrm{O}_{2}, \mathrm{Ti}_{0.6} \mathrm{Fe}_{0.4} \mathrm{O}_{2,}{ }^{67} \mathrm{Ti}_{0.8-x / 4} \mathrm{Fe}_{x / 2} \mathrm{Co}_{0.2-x / 4} \mathrm{O}_{2}(0 \leq x \leq 0.8)^{68}$, and $\mathrm{Ti}_{(5.2-2 \mathrm{x}) / 6} \mathrm{Mn}_{\mathrm{x} / 2} \mathrm{O}_{2}(0 \leq \mathrm{x} \leq$ $0.4)^{69}$, and $\mathrm{Co}_{1 / 3} \mathrm{Al}_{2 / 3}(\mathrm{OH})_{2}$. Spin-glass behavior was recently observed in the dried aggregate of tetramethylammonium (TMA)/ $\mathrm{MnO}_{2}$ nanosheets, in which the geometrical frustration was caused by the triangular arrangement of the mixed-valence $\mathrm{Mn}^{4+} / \mathrm{Mn}^{3+}$ ions in the $\mathrm{MnO}_{2}$ layer. ${ }^{70}$

Concerning applications, ferromagnetic nanosheets have become a pivotal architectural element in magneto-optical (MO) and magneto-electronic devices, because low-dimensional nanostructures make use of the advantage offered by spin-polarized electrons and realize the integration of ferromagnetic materials into nanoelectronics. Indeed, the 2D nature of the electronic state of ferromagnetic nanosheets leads to a gigantic MO response, superior to that of bulk systems (Fig. 8). Multilayer films of $\mathrm{Ti}_{0.8} \mathrm{Co}_{0.2} \mathrm{O}_{2}$ and $\mathrm{Ti}_{0.6} \mathrm{Fe}_{0.4} \mathrm{O}_{4}$ nanosheets exhibited a robust $\mathrm{MO}$ effect $\left(\sim 10^{4} \mathrm{deg} \mathrm{cm}^{-1}\right)$ near the absorption edge at $280 \mathrm{~nm}$, the shortest operating wavelength attained so far. ${ }^{67}$ More interestingly, alternating stacking $\left(\mathrm{Ti}_{0.8} \mathrm{Co}_{0.2} \mathrm{O}_{2} / \mathrm{Ti}_{0.6} \mathrm{Fe}_{0.4} \mathrm{O}_{2}\right)_{5}$ caused a strong enhancement in $\mathrm{MO}$ response $\left(\sim 3 \times 10^{5} \mathrm{deg} \mathrm{cm}^{-1}\right)$ at $400-550 \mathrm{~nm}$, which stems from the interlayer $d-d$ transitions $\left(\mathrm{Co}^{2+}-\mathrm{Fe}^{3+}\right)$ between adjacent nanosheets. ${ }^{67}$ A similar $\mathrm{MO}$ response $\left(\sim 2 \times 10^{5} \mathrm{deg} \mathrm{cm}^{-1}\right)$ at $400-750 \mathrm{~nm}$ was also observed in $(\mathrm{Co} / \mathrm{Fe})$-cosubstituted titania nanosheets, $\mathrm{Ti}_{0.8-x / 4} \mathrm{Fe}_{x / 2} \mathrm{Co}_{0.2-x / 4} \mathrm{O}_{2}(x=0.2,0.4,0.6) .{ }^{68}$ These 
MO materials are also important from a practical viewpoint as a key component for optical isolators in optical communication and data storage devices. In particular, such a large MO response including the blue light region offers potential for short-wavelength MO applications.
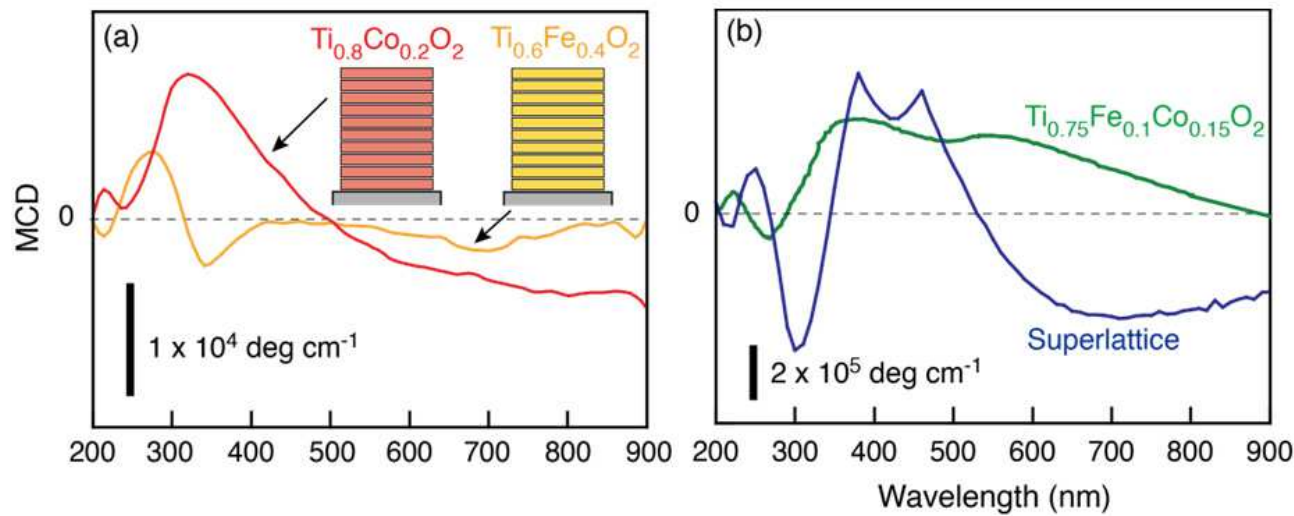

Fig. 8. (a) Magneto-optical spectra for multilayer assemblies of $\left(\mathrm{Ti}_{0.8} \mathrm{Co}_{0.2} \mathrm{O}_{2}\right)_{10}$ and $\left(\mathrm{Ti}_{0.6} \mathrm{Fe}_{0.4} \mathrm{O}_{2}\right)_{10}$. (b) Magneto-optical spectra for $\left(\mathrm{Ti}_{0.8} \mathrm{Co}_{0.2} \mathrm{O}_{2} / \mathrm{Ti}_{0.6} \mathrm{Fe}_{0.4} \mathrm{O}_{2}\right)_{5}$ superlattice and $\left(\mathrm{Ti}_{0.75} \mathrm{Fe}_{0.1} \mathrm{Co}_{0.15} \mathrm{O}_{2}\right)_{10}$. We used magnetic circular dichroism (MCD) spectroscopy for the characterization of nanosheets. The MCD spectra were measured at RT on the basis of the difference in the absorption of right and left circularly polarized light. $1^{\circ}$ of MCD corresponds to a $7 \%$ difference of optical absorption.

These ferromagnetic nanosheets are also a model experimental system for future spintronics studies, and their assembly has great potential for the rational design and construction of complex nanodevices, even combined with transparent electronics and molecular devices. Although we focus here only on MO devices, the assembled structure is naturally viewed as a tunnel junction, which could obviously be used in novel devices such as spin-tunneling switches, spin valves and optical interconnectors.

\section{Conclusion}

The current status of research on oxide nanosheets was reviewed. A variety of physical and chemical properties of oxide nanosheets have been developed to functionalize nanosheets for electronic and spin-electronic applications, and further studies will yield new information on their physics.

2D nanosheets also teach us how to handle and process 2D nanomaterials and develop nanotechnology in general. Although we have focused here only on high- $\kappa$ properties in oxide nanosheets, 2D nanosheets exist in a whole class of functional materials, including metals, semiconductors, ferromagnetic, redox-active, photoluminescence, photochromic etc. $2 \mathrm{D}$ nanosheets with having regulated 2D would create the unconventional interactions of electrons as well as the confinements of electrons and ions inside the 2D nanospace or quantum well. Through new chemical design of 2D nanosheets, we can expect new or unprecedented functionalities in the 2D confined system. Furthermore, we can utilize 
nanosheet-based LbL technology as a new tool to develop advanced fusion functions by promoting the cooperative interaction between organized components, which are difficult to attain with the current synthetic techniques and thin-film technologies.

Oxide nanosheets provide an ideal model to study phenomena in 2D systems. Previously restricted to theoretical study, 2D nanomaterials with their exotic properties are now open to experimentation using the individual 2D system. Graphene has already been found to exhibit a number of unique phenomena such as anomalous quantum Hall effect, bipolar supercurrent, half-metallic, etc. Although current experimental and theoretical efforts mainly focus on graphene, similar properties may be available with oxide nanosheets. We hope that all aspects described here demonstrate the great potential of oxide nanosheets, introducing more exciting physics and wide-ranging applications.

\section{Acknowledgements}

The authors are grateful to Dr. K. Takada, Dr. Y. Ebina, Dr. R. Ma, Dr. T. C. Ozawa, Dr. T. Shibata, Dr. K. Fukuda, Dr. K. Akatsuka, Dr. B-W. Li, and Genki Takanashi (NIMS), Prof. H. Funakubo (TIT), Prof. T. Kiguchi (Tohoku U.), and Prof. K. Ono (KEK) for their experimental contributions and stimulating discussions over the years of the authors' researches of oxide nanosheets. This work was in part supported by World Premier International Research Center Initiative (WPI Initiative on Materials Nanoarchitronics), MEXT, CREST, JST, the Industrial Technology Research Grant Program (06A22702d), NEDO, the Grant-in-Aid for Scientific research (Fusion Materials 2106), MEXT, and Murata Foundation, Japan.

\section{References}

[1] Novoselov, K. S.; Geim, A. K.; Morozov, S. V.; Jiang, D.; Zhang, Y.; Dubonos, S. V.; Grigorieva, I. V.; Firsov, A. A., Electric field effect in atomically thin carbon films. Science 2004, 306, 666-669.

[2] Geim, A. K.; Novoselov, K. S., The rise of graphene. Nature Materials 2007, 6, 183-191.

[3] Sasaki, T., Fabrication of nanostructured functional materials using exfoliated nanosheets as a building block. J. Ceram. Soc. Jpn. 2007, 115, 9-16.

[4] Osada, M.; Sasaki, T., Exfoliated oxide nanosheets: new solution to nanoelectronics. J. Mate. Chem. 2009, 19, 2503.

[5] Ma, R. Z.; Sasaki, T., Nanosheets of oxides and hydroxides: Ultimate 2D charge-bearing functional crystallites. Adv. Mater. 2010, 22, 5082-5104.

[6] Golberg, D., NANOMATERIALS Exfoliating the inorganics. Nature Nanotech. 2011, 6, 200-201.

[7] Schaak, R. E.; Mallouk, T. E., Self-assembly of tiled perovskite monolayer and multilayer thin films. Chem. Mater. 2000, 12, 2513-2516.

[8] Sasaki, T.; Ebina, Y.; Tanaka, T.; Harada, M.; Watanabe, M.; Decher, G., Layer-by-layer assembly of titania nanosheet/polycation composite films. Chem. Mater. 2001, 13, 4661-4667.

[9] Schaak, R. E.; Mallouk, T. E., Perovskites by design: A toolbox of solid-state reactions. Chem. Mater. 2002, 14, 1455-1471.

[10] Ebina, Y.; Sasaki, T.; Harada, M.; Watanabe, M., Restacked perovskite nanosheets and their Pt-loaded materials as photocatalysts. Chem. Mater. 2002, 14, 4390-4395. 
[11] Wang, Z.-S.; Sasaki, T.; Muramatsu, M.; Ebina, Y.; Tanaka, T.; Wang; Watanabe, M., Self-assembled multilayers of titania nanoparticles and nanosheets with polyelectrolytes. Chem. Mater. 2003, 15, 807-812.

[12] Wang, Z.-S.; Ebina, Y.; Takada, K.; Watanabe, M.; Sasaki, T., Inorganic multilayer assembly of titania semiconductor nanosheets and Ru complexes. Langmuir 2003, 19, 9534-9537.

[13] Wang; Omomo, Y.; Sakai, N.; Fukuda, K.; Nakai, I.; Ebina, Y.; Takada, K.; Watanabe, M.; Sasaki, T., Fabrication and characterization of multilayer ultrathin films of exfoliated $\mathrm{MnO}_{2}$ nanosheets and polycations. Chem. Mater. 2003, 15, 2873-2878.

[14] Wang; Takada, K.; Kajiyama, A.; Onoda, M.; Michiue, Y.; Zhang; Watanabe, M.; Sasaki, T., Synthesis of a Li,Mn-oxide with disordered layer stacking through flocculation of exfoliated $\mathrm{MnO}_{2}$ nanosheets, and its electrochemical properties. Chem. Mater. 2003, 15, 4508-4514.

[15] Xin, H.; Ma, R.; Wang, L. Z.; Ebina, Y.; Takada, K.; Sasaki, T., Appl. Phys. Lett. 2004, 85, 4187.

[16] Wang, L.; Ebina, Y.; Takada, K.; Sasaki, T., Ultrathin hollow nanoshells of manganese oxide. Chem. Commun. 2004, 1074-1075.

[17] Wang, L. Z.; Ebina, Y.; Takada, K.; Kurashima, K.; Sasaki, T., A new mesoporous manganese oxide pillared with double layers of alumina. Adv. Mater. 2004, 16, 14121416.

[18] Wang; Ebina, Y.; Takada, K.; Sasaki, T., Ultrathin films and hollow shells with pillared architectures fabricated via layer-by-layer self-assembly of titania nanosheets and aluminum keggin ions. J. Phys. Chem. B 2004, 108, 4283-4288.

[19] Sasaki, T.; Watanabe, M.; Hashizume, H.; Yamada, H.; Nakazawa, H., Macromoleculelike aspects for a colloidal suspension of an exfoliated titanate. Pairwise association of nanosheets and dynamic reassembling process initiated from it. J. Am. Chem. Soc. 1996, 118, 8329-8335.

[20] Sasaki, T.; Watanabe, M., Osmotic swelling to exfoliation. Exceptionally high degrees of hydration of a layered titanate. J. Am. Chem. Soc. 1998, 120, 4682-4689.

[21] Tanaka, T.; Ebina, Y.; Takada, K.; Kurashima, K.; Sasaki, T., Oversized titania nanosheet crystallites derived from flux-grown layered titanate single crystals. Chem. Mater. 2003, 15, 3564-3568.

[22] Sugimoto, W.; Terabayashi, O.; Murakami, Y.; Takasu, Y., Electrophoretic deposition of negatively charged tetratitanate nanosheets and transformation into preferentially oriented $\mathrm{TiO}_{2}$ (B) film. J. Mater. Chem. 2002, 12, 3814-3818.

[23] Omomo, Y.; Sasaki, T.; Wang, L. Z.; Watanabe, M., Redoxable nanosheet crystallites of $\mathrm{MnO}_{2}$ derived via delamination of a layered manganese oxide. J. Am. Chem. Soc. 2003, 125, 3568-3575.

[24] Takagaki, A.; Sugisawa, M.; Lu, D. L.; Kondo, J. N.; Hara, M.; Domen, K.; Hayashi, S., Exfoliated nanosheets as a new strong solid acid catalyst. J. Am. Chem. Soc. 2003, $125,5479-5485$.

[25] Takagaki, A.; Yoshida, T.; Lu, D.; Kondo, J. N.; Hara, M.; Domen, K.; Hayashi, S., Titanium niobate and titanium tantalate nanosheets as strong solid acid catalysts. J. Phys. Chem. B 2004, 108, 11549-11555.

[26] Fukuda, K.; Nakai, I.; Ebina, Y.; Ma, R. Z.; Sasaki, T., Colloidal unilamellar layers of tantalum oxide with open channels. Inorg. Chem. 2007, 46, 4787-4789. 
[27] Kim, D. S.; Ozawa, T. C.; Fukuda, K.; Ohshima, S.; Nakai, I.; Sasaki, T., Soft-Chemical Exfoliation of $\mathrm{Na}_{0.9} \mathrm{Mo}_{2} \mathrm{O}_{4}$ : Preparation and Electrical Conductivity Characterization of a Molybdenum Oxide Nanosheet. Chem. Mater. 2011, 23, 27002702.

[28] Sugimoto, W.; Iwata, H.; Yasunaga, Y.; Murakami, Y.; Takasu, Y., Preparation of ruthenic acid nanosheets and utilization of its interlayer surface for electrochemical energy storage. Angew. Chem. Int. Ed. 2003, 42, 4092-4096.

[29] Fukuda, K.; Akatsuka, K.; Ebina, Y.; Ma, R.; Takada, K.; Nakai, I.; Sasaki, T., Exfoliated nanosheet crystallite of cesium tungstate with 2D pyrochlore structure: Synthesis, characterization, and photochromic properties. ACS Nano 2008, 2, 1689-1695.

[30] Treacy, M. M. J.; Rice, S. B.; Jacobson, A. J.; Lewandowski, J. T., Electron microscopy study of delamination in dispersions of the perovskite-related layered phases $\mathrm{K}\left[\mathrm{Ca}_{2} \mathrm{Na}_{\mathrm{n}-3} \mathrm{Nb}_{\mathrm{n}} \mathrm{O}_{3 \mathrm{n}-1}\right]$ : evidence for single-layer formation. Chem. Mater. 1990, 2, 279286.

[31] Ebina, Y.; Sasaki, I.; Watanabe, A., Study on exfoliation of layered perovskite-type niobates. Solid State Ionics 2002, 151, 177-182.

[32] Ozawa, T. C.; Fukuda, K.; Akatsuka, K.; Ebina, Y.; Sasaki, T., Preparation and Characterization of the $\mathrm{Eu}^{3+}$ Doped Perovskite Nanosheet Phosphor: $\mathrm{La}_{0.90} \mathrm{Eu}_{0.05} \mathrm{Nb}_{2} \mathrm{O}_{7}$. Chem. Mater. 2007, 19, 6575-6580.

[33] Ida, S.; Ogata, C.; Unal, U.; Izawa, K.; Inoue, T.; Altuntasoglu, O.; Matsumoto, Y., Preparation of a blue luminescent nanosheet derived from layered perovskite $\mathrm{Bi}_{2} \mathrm{SrTa}_{2} \mathrm{O}_{9}$. J. Am. Chem. Soc. 2007, 129, 8956-8959.

[34] Ozawa, T. C.; Fukuda, K.; Akatsuka, K.; Ebina, Y.; Sasaki, T.; Kurashima, K.; Kosuda, $\mathrm{K} .,\left(\mathrm{K}_{1.5} \mathrm{Eu}_{0.5}\right) \mathrm{Ta}_{3} \mathrm{O}_{10}$ : A far-red luminescent nanosheet phosphor with the double perovskite structure. J. Phys. Chem. C 2008, 112, 17115-17120.

[35] Ida, S.; Ogata, C.; Eguchi, M.; Youngblood, W. J.; Mallouk, T. E.; Matsumoto, Y., Photoluminescence of perovskite nanosheets prepared by exfoliation of layered oxides, $\mathrm{K}_{2} \mathrm{Ln}_{2} \mathrm{Ti}_{3} \mathrm{O}_{10}, \mathrm{KLnNb}_{2} \mathrm{O}_{7}$, and $\mathrm{RbLnTa}_{2} \mathrm{O}_{7}$ (Ln : lanthanide ion). J. Am. Chem. Soc. 2008, 130, 7052-7059.

[36] Fukuda, K.; Nakai, I.; Oishi, C.; Nomura, M.; Harada, M.; Ebina, Y.; Sasaki, T., Nanoarchitecture of semiconductor titania nanosheets revealed by polarizationdependent total reflection fluorescence X-ray absorption fine structure. J. Phys. Chem. B 2004, 108, 13088-13092.

[37] Xu, F. F.; Bando, Y.; Ebina, Y.; Sasaki, T., Modification of crystal structures in perovskite-type niobate nanosheets. Philosophical Magazine a-Physics of Condensed Matter Structure Defects and Mechanical Properties 2002, 82, 2655-2663.

[38] Xu, F. F.; Bando, Y.; Ebina, Y.; Sasaki, T., Stacking-fault pyramids formed in perovskitetype niobate nanosheet aggregates under electron irradiation. Philosophical Magazine Letters 2003, 83, 367-373.

[39] Xu, F. F.; Ebina, Y.; Bando, Y.; Sasaki, T., Structural characterization of (TBA, $\mathrm{H}) \mathrm{Ca}_{2} \mathrm{Nb}_{3} \mathrm{O}_{10}$ nanosheets formed by delamination of a precursor-layered perovskite. J. Phys. Chem. B 2003, 107, 9638-9645.

[40] Xu, F. F.; Ebina, Y.; Bando, Y.; Sasaki, T., In-situ transmission electron microscopic study of perovskite-type niobate nanosheets under electron-irradiation and heating. J. Phys. Chem. B 2003, 107, 6698-6703. 
[41] Decher, G., Fuzzy nanoassemblies: Toward layered polymeric multicomposites. Science 1997, 277, 1232-1237.

[42] Muramatsu, M.; Akatsuka, K.; Ebina, Y.; Wang, K. Z.; Sasaki, T.; Ishida, T.; Miyake, K.; Haga, M., Fabrication of densely packed titania nanosheet films on solid surface by use of Langmuir-Blodgett deposition method without amphiphilic additives. Langmuir 2005, 21, 6590-6595.

[43] Osada, M.; Akatsuka, K.; Ebina, Y.; Kotani, Y.; Ono, K.; Funakubo, H.; Ueda, S.; Kobayashi, K.; Takada, K.; Sasaki, T., Langmuir-Blodgett fabrication of nanosheetbased dielectric films without an interfacial dead layer. Jpn. J. Appl. Phys. 2008, 47, 7556-7560.

[44] Akatsuka, K.; Haga, M.; Ebina, Y.; Osada, M.; Fukuda, K.; Sasaki, T., Construction of highly ordered lamellar nanostructures through Langmuir-Blodgett deposition of molecularly thin titania nanosheets tens of micrometers wide and their excellent dielectric properties. ACS Nano 2009, 3, 1097-1106.

[45] Li, B. W.; Osada, M.; Ozawa, T. C.; Ebina, Y.; Akatsuka, K.; Ma, R. Z.; Funakubo, H.; Sasaki, T., Engineered interfaces of artificial perovskite oxide superlattices via nanosheet deposition process. ACS Nano 2010, 4, 6673-6680.

[46] Osada, M.; Akatsuka, K.; Ebina, Y.; Funakubo, H.; Ono, K.; Takada, K.; Sasaki, T., Robust High-k response in molecularly thin perovskite nanosheets. ACS Nano 2010, 4, 5225-5232.

[47] Geim, A. K.; MacDonald, A. H., Graphene: Exploring carbon flatland. Physics Today 2007, 60, 35-41.

[48] Sato, H.; Ono, K.; Sasaki, T.; Yamagishi, A., First-principles study of two-dimensional titanium dioxides. J. Phys. Chem. B 2003, 107, 9824-9828.

[49] Sakai, N.; Ebina, Y.; Takada, K.; Sasaki, T., Electronic band structure of titania semiconductor nanosheets revealed by electrochemical and photoelectrochemical studies. J. Am. Chem. Soc. 2004, 126, 5851-8.

[50] Sasaki, T.; Watanabe, M., Semiconductor nanosheet crystallites of quasi- $\mathrm{TiO}_{2}$ and their optical properties. J. Phys. Chem. B 1997, 101, 10159-10161.

[51] Xin, H.; Ebina, Y.; Ma, R.; Takada, K.; Sasaki, T., Thermally stable luminescent composites fabricated by confining rare earth complexes in the two-dimensional gallery of titania nanosheets and their photophysical properties. J. Phys. Chem. B 2006, 110, 9863-9868.

[52] Osada, M.; Ebina, Y.; Funakubo, H.; Yokoyama, S.; Kiguchi, T.; Takada, K.; Sasaki, T., High-к dielectric nanofilms fabricated from titania nanosheets. Adv. Mater. 2006, 18, 1023-1027.

[53] Osada, M.; Akatsuka, K.; Ebina, Y.; Funakubo, H.; Kiguchi, T.; Takada, K.; Sasaki, T., Solution-based fabrication of high-kappa dielectric nanofilms using titania nanosheets as a building block. Jpn. J. Appl. Phys. 2007, 46, 6979-6983.

[54] Li, B.-W.; Osada, M.; Ozawa, T. C.; Ma, R.; Akatsuka, K.; Ebina, Y.; Funakubo, H.; Ueda, S.; Kobayashi, K.; Sasaki, T., Solution-based fabrication of perovskite nanosheet films and their dielectric properties. Jpn. J. Appl. Phys. 2009, 48, 09KA15.

[55] Li, B. W.; Osada, M.; Ozawa, T. C.; Akatsuka, K.; Ebina, Y.; Ma, R.; Ono, K.; Funakubo, H.; Sasaki, T., A-site-modified perovskite nanosheets and their integration into high-k dielectric thin films with a clean interface. Jpn. J. Appl. Phys. 2010, 49. 
[56] Werner, M. C.; Banerjee, I.; McIntyre, P. C.; Tani, N.; Tanimura, M., Microstructure of $(\mathrm{Ba}, \mathrm{Sr}) \mathrm{TiO}_{3}$ thin films deposited by physical vapor deposition at 480 degrees $\mathrm{C}$ and its influence on the dielectric properties. Appl. Phys. Lett. 2000, 77, 1209-1211.

[57] Hwang, C. S., Thickness-dependent dielectric constants of $(\mathrm{Ba}, \mathrm{Sr}) \mathrm{TiO}_{3}$ thin films with Pt or conducting oxide electrodes. J. Appl. Phys. 2002, 92, 432-437.

[58] Suzuki, S.; Miyayama, M., Lithium intercalation properties of octatitanate synthesized through exfoliation/reassembly. J. Phys. Chem. B 2006, 110, 4731-4734.

[59] Suzuki, S.; Miyayama, M., Lithium intercalation properties of reassembled titanate/carbon composites. J. Electrochem. Soc. 2007, 154, A438-A443.

[60] Suzuki, S.; Miyayama, M., Microstructural controls of titanate nanosheet composites using carbon fibers and high-rate electrode properties for lithium ion secondary batteries. J. Power Sources 2011, 196, 2269-2273.

[61] Sakai, N.; Fukuda, K.; Omomo, Y.; Ebina, Y.; Takada, K.; Sasaki, T., Heteronanostructured films of titanium and manganese oxide nanosheets: Photoinduced charge transfer and electrochemical properties. J. Phys. Chem. C 2008, 112, 51975202.

[62] Shibata, T.; Ebina, Y.; Ohnishi, T.; Takada, K.; Kogure, T.; Sasaki, T., Fabrication of anatase thin film with perfect c-axis orientation on glass substrate promoted by a two-dimensional perovskite nanosheet seed layer. Crystal Growth \& Design 2010, 10, 3787-3793.

[63] Shibata, T.; Fukuda, K.; Ebina, Y.; Kogure, T.; Sasaki, T., One-nanometer-thick seed layer of unilamellar nanosheets promotes oriented growth of oxide crystal films. Adv. Mater. 2008, 20, 231-+.

[64] Shibata, T.; Ohnishi, T.; Sakaguchi, I.; Osada, M.; Takada, K.; Kogure, T.; Sasaki, T., Well-controlled crystal growth of zinc oxide films on plastics at room temperature using 2D nanosheet seed layer. J. Phys. Chem. C 2009, 113, 19096-19101.

[65] Osada, M.; Ebina, Y.; Fukuda, K.; Ono, K.; Takada, K.; Yamaura, K.; TakayamaMuromachi, E.; Sasaki, T., Ferromagnetism in two-dimensional $\mathrm{Ti}_{0.8} \mathrm{Co}_{0.2} \mathrm{O}_{2}$ nanosheets. Phys. Rev. B 2006, 73.

[66] Kotani, Y.; Taniuchi, T.; Osada, M.; Sasaki, T.; Kotsugi, M.; Guo, F. Z.; Watanabe, Y.; Kubota, M.; Ono, K., X-ray nanospectroscopic characterization of a molecularly thin ferromagnetic Ti1-xCoxO2 nanosheet. Appl. Phys. Lett. 2008, 93.

[67] Osada, M.; Ebina, Y.; Takada, K.; Sasaki, T., Gigantic magneto-optical effects in multilayer assemblies of two-dimensional titania nanosheets. Adv. Mater. 2006, 18, 295-+.

[68] Osada, M.; Itose, M.; Ebina, Y.; Ono, K.; Ueda, S.; Kobayashi, K.; Sasaki, T., Gigantic magneto-optical effects induced by $(\mathrm{Fe} / \mathrm{Co})$-cosubstitution in titania nanosheets. Appl. Phys. Lett. 2008, 92.

[69] Dong, X. P.; Osada, M.; Ueda, H.; Ebina, Y.; Kotani, Y.; Ono, K.; Ueda, S.; Kobayashi, K.; Takada, K.; Sasaki, T., Synthesis of Mn-substituted titania nanosheets and ferromagnetic thin films with controlled doping. Chem. Mater. 2009, 21, 4366-4373.

[70] Kai, K.; Yoshida, Y.; Kageyama, H.; Saito, G.; Ishigaki, T.; Furukawa, Y.; Kawamata, J., Room-temperature synthesis of manganese oxide monosheets. J. Am. Chem. Soc. $2008,130,15938-15943$. 


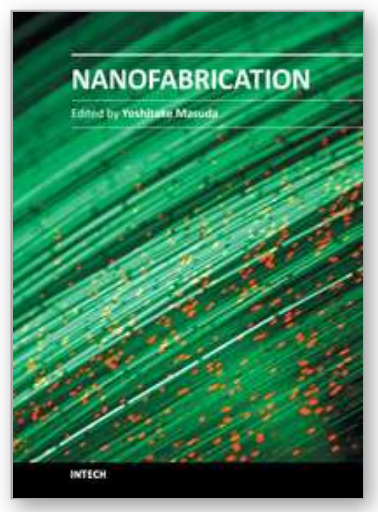

\author{
Nanofabrication \\ Edited by Dr. Yoshitake Masuda
}

ISBN 978-953-307-912-7

Hard cover, 354 pages

Publisher InTech

Published online 22, December, 2011

Published in print edition December, 2011

We face many challenges in the 21st century, such as sustainably meeting the world's growing demand for energy and consumer goods. I believe that new developments in science and technology will help solve many of these problems. Nanofabrication is one of the keys to the development of novel materials, devices and systems. Precise control of nanomaterials, nanostructures, nanodevices and their performances is essential for future innovations in technology. The book "Nanofabrication" provides the latest research developments in nanofabrication of organic and inorganic materials, biomaterials and hybrid materials. I hope that "Nanofabrication" will contribute to creating a brighter future for the next generation.

\title{
How to reference
}

In order to correctly reference this scholarly work, feel free to copy and paste the following:

Minoru Osada and Takayoshi Sasaki (2011). Chemical Nanomanipulation of Two-Dimensional Nanosheets and Its Applications, Nanofabrication, Dr. Yoshitake Masuda (Ed.), ISBN: 978-953-307-912-7, InTech, Available from: http://www.intechopen.com/books/nanofabrication/chemical-nanomanipulation-of-twodimensional-nanosheets-and-its-applications

\section{INTECH}

open science | open minds

\section{InTech Europe}

University Campus STeP Ri

Slavka Krautzeka 83/A

51000 Rijeka, Croatia

Phone: +385 (51) 770447

Fax: +385 (51) 686166

www.intechopen.com

\section{InTech China}

Unit 405, Office Block, Hotel Equatorial Shanghai

No.65, Yan An Road (West), Shanghai, 200040, China

中国上海市延安西路65号上海国际贵都大饭店办公楼 405 单元

Phone: +86-21-62489820

Fax: +86-21-62489821 
(C) 2011 The Author(s). Licensee IntechOpen. This is an open access article distributed under the terms of the Creative Commons Attribution 3.0 License, which permits unrestricted use, distribution, and reproduction in any medium, provided the original work is properly cited. 